\title{
Arx and Nkx2.2 compound deficiency redirects pancreatic alpha- and beta-cell differentiation to a somatostatin/ghrelin co-expressing cell lineage
}

\author{
Simon Kordowich ${ }^{1}$, Patrick Collombat ${ }^{2,3^{*}+}$, Ahmed Mansouri ${ }^{1,4^{*}+}$ and Palle Serup ${ }^{5+}$
}

\begin{abstract}
Background: Nkx2.2 and Arx represent key transcription factors implicated in the specification of islet cell subtypes during pancreas development. Mice deficient for Arx do not develop any alpha-cells whereas beta- and delta-cells are found in considerably higher numbers. In Nkx2.2 mutant animals, alpha- and beta-cell development is severely impaired whereas a ghrelin-expressing cell population is found augmented.

Notably, Arx transcription is clearly enhanced in Nkx2.2-deficient pancreata. Hence in order to precise the functional link between both factors we performed a comparative analysis of Nkx2.2/Arx single- and double-mutants but also of Pax6-deficient animals.

Results: We show that most of the ghrelin ${ }^{+}$cells emerging in pancreata of Nkx2.2- and Pax6-deficient mice, express the alpha-cell specifier Arx, but also additional beta-cell related genes. In Nkx2.2-deficient mice, Arx directly co-localizes with iAPP, PC1/3 and Pdx1 suggesting an Nkx2.2-dependent control of Arx in committed beta-cells. The combined loss of $N k \times 2.2$ and Arx likewise results in the formation of a hyperplastic ghrelin ${ }^{+}$cell population at the expense of mature alpha- and beta-cells. Surprisingly, such $N k \times 2.2^{-1-} A r x$ ghrelin ${ }^{+}$cells also express the somatostatin hormone.

Conclusions: Our data indicate that Nkx2.2 acts by reinforcing the transcriptional networks initiated by Pax4 and Arx in early committed beta- and alpha-cell, respectively. Our analysis also suggests that one of the coupled functions of Nkx2.2 and Pax4 is to counteract Arx gene activity in early committed beta-cells.
\end{abstract}

Keywords: Arx, Nkx2.2, somatostatin, ghrelin, Pax6, Pax4

\section{Background}

The pancreas is comprised of acinar and duct cells (exocrine compartment), producing and transporting digestive enzymes and bicarbonate, as well as endocrine cells, which secrete hormones to the blood stream. The latter are aggregated into scattered clusters of cells, termed islets of Langerhans. These are typically composed of five cell subtypes, including alpha-, beta-, delta-, epsilonand PP-cells that produce the hormones glucagon, insulin, somatostatin, ghrelin, and pancreatic polypeptide (PP), respectively. Insulin and glucagon are secreted co-

\footnotetext{
* Correspondence: collombat@unice.fr; amansou@gwdg.de

+ Contributed equally

'Department of Molecular Cell Biology, Max-Planck Institute for Biophysical Chemistry, Am Fassberg, D-37077 Göttingen, Germany

2Diabetes Genetics team, Inserm U636, FR-06108 Nice, France

Full list of author information is available at the end of the article
}

ordinately to control glucose homeostasis, whereas somatostatin and PP regulate the secretion of other hormones and of exocrine enzymes [1-5]. The hormone ghrelin has been shown to possess orexigenic properties and to play a role in glucose-stimulated insulin secretion $[6,7]$.

During pancreas development, the first wave of endocrine cell differentiation begins at embryonic day (E) 9 and results in the emergence of glucagon-producing cells, followed by the appearance of few insulin-producing cells, often co-expressing glucagon [8-12]. Ghrelinexpressing cells can be detected from E10.5 on $[2,13]$. Subsequently, the major wave of endocrine cell formation ("secondary transition"), initiates around E13 and results in the emergence of numerous insulin-producing beta-cells and glucagon-producing alpha-cells. Around

\section{Biomed Central}


E15, the first somatostatin-producing delta-cells emerge [10] while, shortly before birth, PP-expressing PP-cells differentiate. Concurrently, from E14 on, the endocrine cell mass continuously expands and self-organizes into well-shaped islets, a process lasting until approximately 4 weeks postpartum [14].

A number of transcriptional regulators have been shown to have crucial roles in controlling the specification of pancreatic cells. Among these, Pdx1 was found to exert a key function for the pancreatic cell lineage allocation. Later during pancreatic development, Pdx1 activity is restricted to beta-cells and a subpopulation of delta-cells [9,15-17]. The expression of the basic helixloop-helix transcription factor Ngn3 induces endocrine differentiation, as evidenced by gain- and loss-of-function studies as well as genetic lineage tracing [18-21]. The specification towards the distinct endocrine cell types was found controlled by the concerted activities of specific transcription factors, including the homedomain-containing factors Nkx2.2 [22], Nkx6.1 [23], Pax6 [24], Brn4 [25], Pax4 [26] and Arx [27].

Nkx2.2 is broadly expressed in the early undifferentiated pancreatic epithelium and in endocrine progenitors. Along with the secondary transition, Nkx2.2 expression becomes restricted to mature beta-cells and a subset of alpha- and PP-cells, whereas it is not detected in delta-cells (reviewed in [28]). Accordingly, mice depleted in $N k x 2.2$ display a complete beta-cell loss and reduced alpha- and PP-cell content, while the numbers of delta-cells remain unchanged. Notably, the ghrelin ${ }^{+}$ cell population appears considerably augmented [13,22]. In this context, it has been shown that Nkx2.2 is decisive for the maintenance of normal beta-cell function and that the transcriptional repressor activity of $\mathrm{Nkx} 2.2$ is required for the proper specification of alpha-cells $[29,30]$. Nkx6.1 has been found essential for the specification of multipotent progenitors towards the duct-/ endocrine-fates in early pancreas development [31]. Post second transition, Nkx6.1 becomes exclusively restricted to developing beta-cells; at that stage it is essential for their expansion [23]. The Pax gene family member, Pax6, is produced in all endocrine cells throughout pancreas development with one exception that is a subpopulation of epsilon-cells $[13,24]$. Thus, in the absence of functional Pax6, alpha-, beta-, delta- and PP-cells are negatively affected with a near complete loss of glucagon-expression from alpha-cells [24,25,32]. Similar to Nkx2.2 mutants, the endocrine portion in $\mathrm{Pax6}^{-/-}$pancreata mainly consists of cells expressing the ghrelinhormone [2]. Pax4, another Pax family member, has been found essential for the formation of beta- and delta-cells [26,33]. Lineage tracing studies revealed that $\mathrm{Pax}_{4}^{+}$precursor cells give rise to all four major endocrine cell types (beta-, alpha-, delta- and PP-cells) [34].
Nevertheless, in the absence of Pax4, beta- and deltacell development is impaired and precursor cells acquire an alpha-cell-like fate, suggesting a predominant role of Pax4 in the differentiation of beta-cells [26,27]. This assumption is supported by recent work demonstrating that the in vivo misexpression of Pax4 in pancreatic/ endocrine progenitors results mainly in the formation of beta-cells. Moreover, the forced and ectopic expression of Pax4 in mature alpha-cells was found sufficient to convert these into functional beta-like cells [35].

Mice lacking the aristaless homeobox gene Arx display a phenotype opposite to the one observed in $\operatorname{Pax}^{-/-}$animals [27]. Depleted in alpha-cells, such mice exhibit proportionally enlarged beta- and delta-cell populations. In fact, a direct and mutually antagonistic transcriptional repression between Arx and Pax4 was previously demonstrated and associated with the specification of the alpha- vs. beta-/delta-cell fates, respectively [36]. This model was further supported by the forced expression of Arx in pancreatic/endocrine progenitors, which led to the favouring of the alpha- but also PP-cell fate, at the expense of beta- and delta-cell lineages [37].

Interestingly, recent analyses of $N k x 2.2$-deficient pancreata outlined a 5 -fold increase in the transcript content of the alpha-cell "specifier" Arx despite an almost complete loss in glucagon-expressing cells [38]. To address this apparent paradox, we undertook a thorough comparative analysis of the endocrine populations arising in pancreata of wild type, $N k x 2.2$ - and Pax6-deficient animals. Moreover, we further analysed the roles of Nkx2.2 and Arx, by characterizing pancreatic endocrine cell fates in mice compound-deficient for $N k \times 2.2$ and Arx.

\section{Results}

\section{Expression of Arx and Brn4 in E16.5 pancreata of wild}

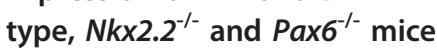

We previously investigated the antagonistic roles of $A r x$ and Pax4 for proper endocrine cell allocation and thereby demonstrated the essential function of Arx in promoting a subset of endocrine precursor cells specifically towards the alpha-cell fate [27,36,37]. The apparent discrepancy between the severely reduced alpha-cell numbers and the 5-fold augmentation in Arx transcripts upon loss of $N k x 2.2$, prompted us to examine the subcellular localization of Arx in pancreata of such mice and thus gain further insights into the role of Arx and Nkx2.2 during endocrine cell specification.

We initially focused our study at E16.5, a developmental stage subsequent to a peak in mature endocrine cell generation. In wild type pancreata, most Arx-labelled cells coexpressed glucagon and were found scattered within the pancreatic tissue (Figure 1A). Only few $\mathrm{Arx}^{+} /$glucagon $^{-}$ cells were detectable, most likely corresponding to alpha- 

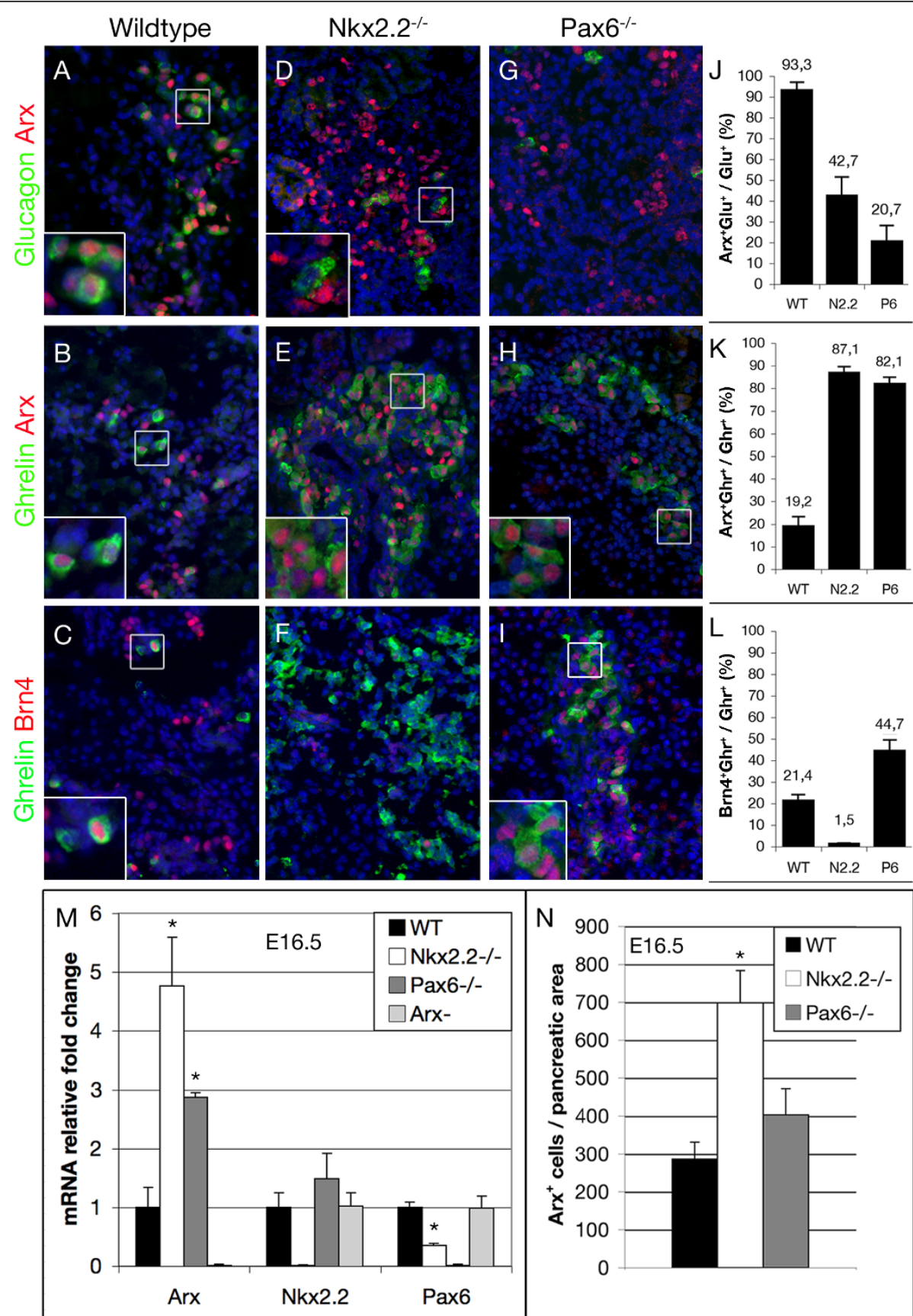

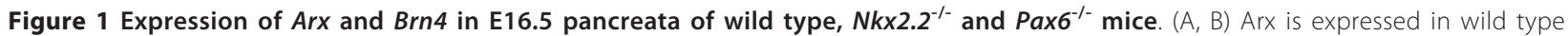
glucagon $^{+}$cells. (A, inset) Moreover, Arx ${ }^{+} /$glucagon $^{-}$cells are detectable at this stage. (B, C, inset) Arx or Brn4 can be detected in a subset of ghrelin $^{+}$cells. (D, inset) In Nkx2.2-mutant pancreata some of the remaining glucagon ${ }^{+}$cells do not express Arx. (E, inset, F) Most Nkx2.2-deficient ghrelin ${ }^{+}$cells express Arx but only rarely Brn4. $(G, H)$ Arx is expressed in pancreata of Pax $6^{-1-}$ mice and co-localizes with most ghrelin ${ }^{+}$cells. Scattered Arx ${ }^{+} /$ghrelin ${ }^{-}$and ghrelin ${ }^{+} /$Arx $^{-}$cells can be detected. (I, inset) Brn4 is expressed in a subset of ghrelin ${ }^{+}$cells and labels a ghrelin cell

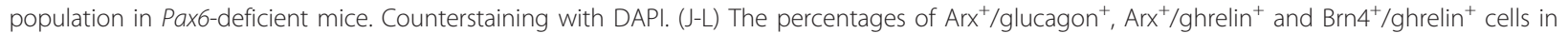

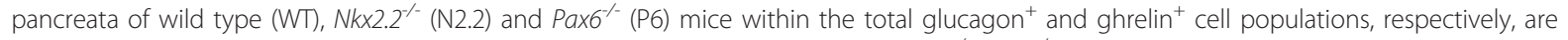

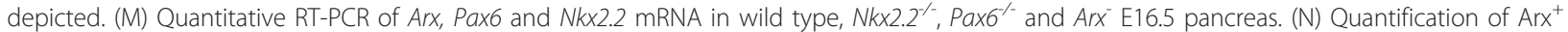

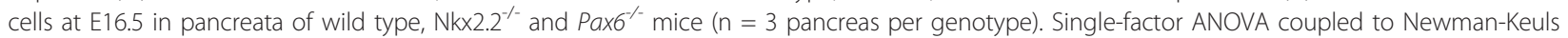
test was applied and $p$-values $<0,05$ were assessed as statistically significant compared to wild type. Statistical significance is achieved with the assumption of a normal distribution. Error bars represent SEM. (original magnification: 400x, Insets magnification: 4x). 
cell precursors that have not yet initiated hormone synthesis. $\mathrm{Arx}^{+}$cells did not express ghrelin, except in rare instances (Figure 1B). Interestingly, in $N k x 2.2$-deficient animals, an almost complete lack of alpha- and beta-cells accompanied by a five-fold increase in Arx transcript levels were noted when compared to their control counterparts ([38], Figure 1M). Subsequent quantifications revealed a 2.4-fold rise in the numbers of Arx-immunoreactive cells in E16.5 mutant pancreata compared to age-matched wild type embryos (Figure 1D, N). Clearly, this number did not fully reflect the upregulation of Arx transcripts, suggesting an increase in Arx production at the single cell level. These results led us to determine whether $N k x 2.2$ expression could be likewise affected in animals deficient for Arx. However, Nkx2.2 transcript levels in E16.5 Arx mutant pancreata were not significantly different from wild type controls, suggesting that $N k x 2.2$ transcription is not regulated by Arx (Figure 1M).

Further analyses of the $\mathrm{Arx}^{+}$cell population in $N k \times 2.2^{-/-}$mice revealed that a vast majority expressed ghrelin. Approximately $90 \%$ of the ghrelin ${ }^{+}$cells were found positive for Arx (Figure 1E, K). Besides this ghrelin ${ }^{+} / \mathrm{Arx}^{+}$population, only few scattered $\mathrm{Arx}^{+} /$ghrelin $^{-}$or ghrelin $^{+} /$Arx $^{-}$cells were detectable in this genotype. Surprisingly, most of the few remaining glucagon-expressing cells present in $N k x 2.2$-deficient pancreata were negative for Arx expression (Figure 1D inset, J). In order to further assess the identity of ghrelin ${ }^{+} / \mathrm{Arx}^{+}$cells, we analysed the expression of the alpha-cell-related marker gene Brn4. Previous analyses of $N k x 2.2$ mutant pancreata had revealed that the numbers of Brn $4^{+}$cells were reduced; correlating with the lower number of glucagon ${ }^{+}$cells [23]. Consistent with these findings, the expression of Brn4 was absent from the hyperplastic ghrelin ${ }^{+}$cells noted in this genotype (Figure 1F, L). Altogether, these results suggest that, in the absence of $N k x 2.2$, the betaand alpha-cell lineages are disfavoured and replaced by a ghrelin ${ }^{+} / \mathrm{Arx}^{+} / \mathrm{Brn}^{-}$cell fate. Considering the crucial role exerted by Arx in promoting the alpha-cell lineage, it is conceivable that such cells correspond to alpha-cell precursors that failed to acquire the full complement of alpha-cell characteristics. However, the observation that the proportion of ghrelin ${ }^{+} / \mathrm{Arx}^{+} / \mathrm{Brn} 4^{-}$cells present in $N k x 2.2^{-1-}$ pancreata is similar to the proportion of betacells normally detected in wild-type mice led us to favour an alternative explanation where cells normally fated towards the beta-cell lineage fail to properly differentiate and ectopically express Arx and ghrelin.

The dramatic increase in Arx transcripts, combined with the profound loss in Pax6 expression in $N k x 2.2$ deficient pancreata (Figure 1M, [13,39]), prompted us to get more insights into putative interplay between these three factors. In Pax6 knockout mice [24,32], the early glucagon $^{+}$population emerging around embryonic day
10.5 is present and properly express the associated markers Brn4 and Isl1 [25]. However, post secondary transition, glucagon ${ }^{+}$cell numbers are significantly reduced (Figure 1G, [24,25]). Consistent with these findings, it was shown that Pax6, both indirectly and directly, potentiates the expression of the glucagon gene [32,40,41]. Interestingly, upon Pax6 deficiency, the betacell population was found reduced concomitantly with a 5.6-fold increase in the numbers of ghrelin ${ }^{+}$cells $[2,24]$. Notably, both $N k x 2.2$ transcript content and expression pattern were found almost normal in $\mathrm{Pax}^{-/-}$pancreata as compared to their wild-type counterparts (Figure 1M, [25]). Surprisingly, in E16.5 Pax6 mutant pancreata, Arx transcripts were found 2.9 times increased as compared to age-matched wild-type pancreata. However, the numbers of $\mathrm{Arx}^{+}$cells were not significantly different from those observed in wild type, indicating that the deficiency in $N k x 2.2$ or Pax6 leads to a similar increase in Arx transcripts at the single cell level (Figure 1M, N). Interestingly, and similar to what we observed in $N k x 2.2$-deficient mice, most of the $\mathrm{Arx}^{+}$cells present in Pax6-deficient pancreata, express ghrelin (Figure $1 \mathrm{H}$, inset). Approximately $80 \%$ of the ghrelin ${ }^{+}$cells were found to express Arx, although scattered $\mathrm{Arx}^{+} /$ghrelin $^{-}$ and ghrelin ${ }^{+} /$Arx $^{-}$cells were also detectable (Figure $1 \mathrm{~K}$ ). The expression of Brn4 appeared unchanged in Pax6deficient mice at E14.5 and E16.5 ([25] and Figure 1I, respectively). Brn4 expression was clearly noted in approximately $45 \%$ of the ghrelin-expressing cells, suggesting at least a partially overlapping expression with Arx (Figure 1L). Notably, beside the ghrelin ${ }^{+} / \mathrm{Brn}^{+}{ }^{+}$cell population, Brn $4^{+}$cells were also found outside of the ghrelin-stained areas (Figure 1I). Together, our data indicate that the reduction of alpha- and beta-cell numbers in $N k \times 2.2^{-/-}$or Pax $6^{-/-}$pancreata is accompanied by an increase in the numbers of cells co-expressing Arx and ghrelin. Interestingly, the loss of Arx does not seem to impact on Nkx2.2 or Pax6 expression.

\section{Comparative analysis of ghrelin $^{+}$cells in pancreata of wild type, $\mathrm{Nk} 2.2^{-/-}$and $\mathrm{Pax}^{-/-}$mice}

To further assess the identity of the ghrelin ${ }^{+} / \mathrm{Arx}^{+}$cell population arising in pancreata of $N k \times 2.2^{-/-}$and $\mathrm{Pax}^{-/-}$ mice, we assayed the expression of a number of betacell-related markers, such as insulin, iAPP, PC1/3 and Pdx1 at E17.5 (Figure 2). Most of these proteins have previously been found expressed in both mutant pancreata, however their expression relative to ghrelin has not been fully resolved $[2,13,42]$.

Previous detailed analyses of wild type ghrelin-expressing cells had led to the conclusion that these could be subdivided into glucagon ${ }^{+}$ghrelin ${ }^{+}$alpha-cells and glucagon $^{-}$ghrelin ${ }^{+}$epsilon-cells. It should be noted that only a subset of alpha-cells were actually found positive for 


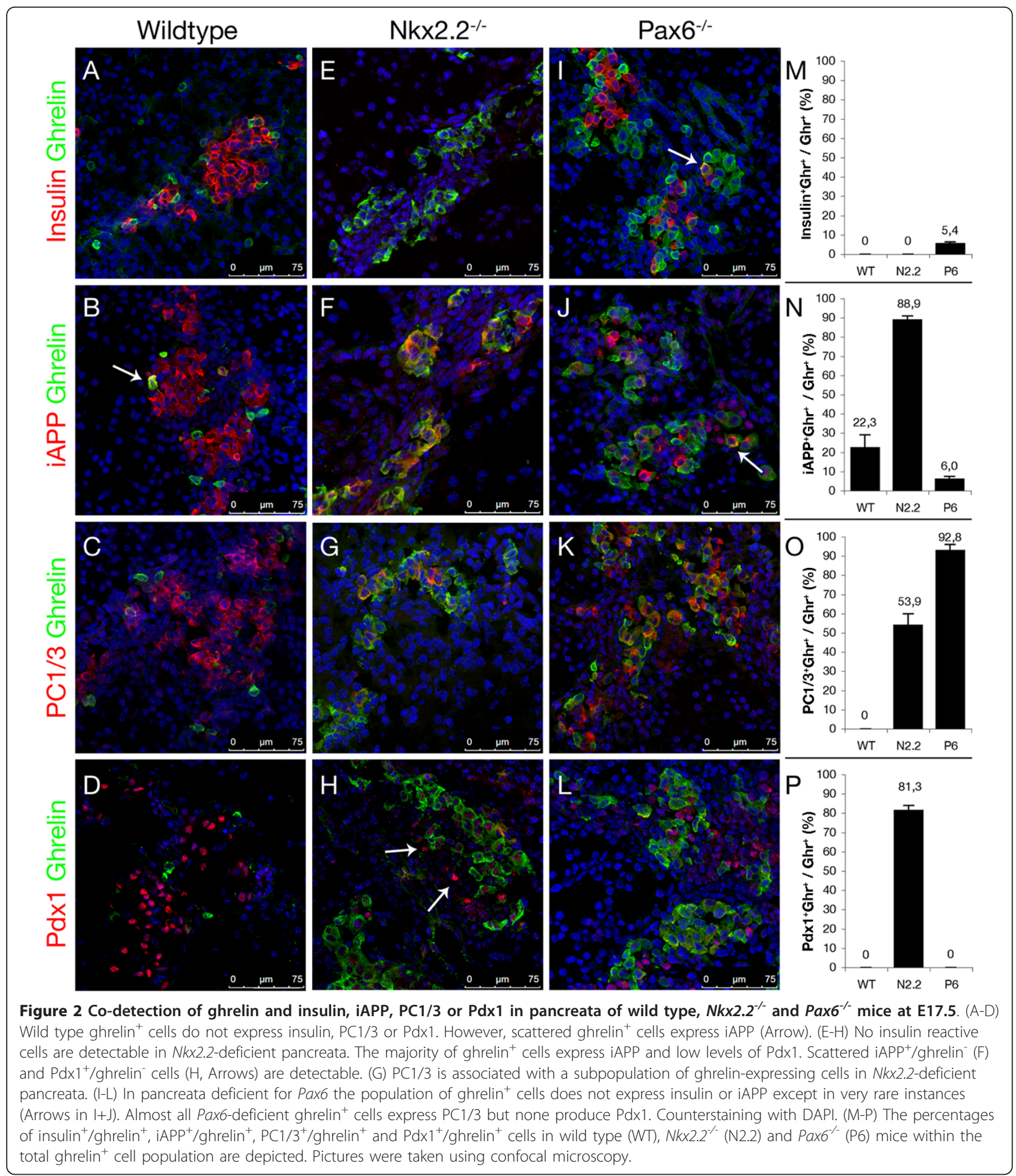

ghrelin, such cells retaining glucagon, Arx and Brn4 expression (Figure 1B, C, [2,13]). For technical reasons, we did not distinguish between these two populations in our analysis of wild type pancreata. Notably, none of the wild type ghrelin ${ }^{+}$cells did express insulin, $\mathrm{PC} 1 / 3$, or Pdx1
(Figure 2A, C, D). However, approximately $20 \%$ of ghrelin ${ }^{+}$cells expressed iAPP at E17.5 (Figure 2B Arrow, N).

Next, we analysed the distribution of these markers within the hyperplastic ghrelin ${ }^{+}$population found in Nkx2.2-deficient pancreata. Notably, Pdx1 expression 
had been detected in these cells, although at markedly lower levels compared to wild type pancreata [22]. Our analysis revealed, that approximately $80 \%$ of ghrelinexpressing cells expressed low levels of $\mathrm{Pdx} 1\left(\mathrm{Pdx} 1^{\text {low }}\right)$ and iAPP in this genotype (Figure $2 \mathrm{H}, \mathrm{P}$ ). Moreover, we frequently detected $\mathrm{Pdx} 1^{+} /$ghrelin ${ }^{-}$cells close to hormone-producing cells in the pancreatic epithelium of such animals (Figure 2H, Arrows). The prohormone convertase $1 / 3$ was found localized in approximately $54 \%$ of ghrelin ${ }^{+}$cells (Figure 2G, O). Thus, the majority of the ghrelin ${ }^{+} / \mathrm{Arx}^{+}$cells that emerge upon $N k x 2.2$ deficiency significantly differ from wild type ghrelin ${ }^{+}$cells. The direct association of these beta-cell markers with ghrelin ${ }^{+}$, and hence with $\mathrm{Arx}^{+}$cells, provides a strong evidence that at least a subpopulation of the ghrelin ${ }^{+} / \mathrm{Arx}^{+}$cells exhibit committed beta-cell characteristics, and do not consist of putative alpha-cell precursors.

Interestingly, similar analyses of the ghrelin ${ }^{+} / \mathrm{Arx}^{+}$ population in Pax6-deficient pancreata outlined different alterations. Notably, a few apparently normal beta-cells develop in the absence of Pax6, these expressing insulin, Pdx1, Hb9, Nkx6.1 and MafA [2,42]. However, we did not detect co-expression of ghrelin and insulin, except in very rare instances (Figure 2I Arrow, M). At comparably low frequencies were detected $\mathrm{iAPP}^{+} /$ghrelin $^{+}$co-expressing cells, however, the bulk of ghrelin ${ }^{+}$cells appeared negative for iAPP (Figure 2J, N). Moreover, and in contrast to the ghrelin ${ }^{+}$population noted in $N k \times 2.2$-deficient pancreata, we did not observe any co-expression of ghrelin and Pdx1 in pancreata of such mice (Figure 2L, [2]). Surprisingly, almost all ghrelin ${ }^{+}$cells were immunoreactive for PC1/3 (Figure 2K, O). Consequently, our data reveal significant differences in the expression profile of ghrelin ${ }^{+}$cells arising in pancreata of $N k \times 2.2^{-1-}$ and $\mathrm{Pax}^{-1-}$ mice. While most ghrelin ${ }^{+}$cells from $N k x 2.2$-deficient embryos are positive for iAPP and Pdx $1^{\text {low }}$, the majority of the $\mathrm{Pax}^{-1-}$ ghrelin-cells do not express these markers. Importantly, the expression of $i A P P$ and $P d x 1$ is not per se impeded upon Pax 6 deficiency as it can clearly be detected outside of the ghrelin-stained areas, probably labelling the remaining beta-cells. Hence, our data supports the notion that, upon the loss of $N k x 2.2$ or Pax6 functional alleles, endocrine precursor cells are still committed towards the beta-cell lineage, do initiate the expression of some beta-cell-specific determinants, but fail to reach a mature beta-cell state and rather misexpress Arx and ghrelin.

Next we assayed the expression of Pdx1, iAPP and $\mathrm{PC} 1 / 3$ in relation with Arx in $N k x 2.2^{-/-}$pancreata. $\mathrm{Arx}^{+}$ cells do not express Pdx1 or PC1/3 in wild type pancreata at E17.5 (Figure 3A, C). Scattered Arx ${ }^{+}$cells coexpress iAPP at this age; however the bulk does not (Figure 3B, inset). In contrast, the majority of the $\mathrm{Arx}^{+}$ cells arising in $N k x 2.2^{-/-}$pancreata do co-express Pdx $1^{\text {low }}$, iAPP or PC1/3 (Figure 3D, Arrows, E, F).

\section{Nkx2.2 ${ }^{--}$Arx mice pancreata lack alpha- and mature beta- cells and exhibit a hyperplastic ghrelin/somatostatin co- positive cell population}

Our results pointing towards a putative failure of betacell development upon $N k x 2.2$ deficiency, prompted us to investigate the role of Arx in this context. Specifically, we asked (1) whether the loss of $N k x 2.2$ is directly responsible for this failure or (2) whether the subsequent increase in $A r x$ expression, resulting from $N k x 2.2$ deficiency, could lead to such phenotypic alteration. To address this issue and gain further insight into the mutual roles of Nkx2.2 and Arx in the processes underlying the specification towards the alpha- and beta-cell lineages, we generated animals doubly mutant for Nkx2.2 and Arx.

Double mutant mice were born following normal Mendelian inheritance, indicating no embryonic lethality. In contrast to their $N k x 2.2$ - and Arx-single mutant littermates surviving until postnatal day (P) 5 and 2, respectively, compound animals did not suckle and died within few hours postpartum. Analyses of their blood glucose levels indicated a hypoglycaemic condition with blood glucose levels lower than $20 \mathrm{mg} / \mathrm{dl}$. Using immunofluorescence, we examined the different endocrine cell populations at P0 (Figure 4). Although Arx-single mutants were found to exhibit a slight increase in the number of beta-cells, we could not detect any insulin-immunoreactive cells in compound mutant pancreata, further demonstrating that functional $N k x 2.2$ is essential for the formation of beta-cells (Figure 4A-D, [27]). As reported in $A r x$-deficient pancreata, glucagon-immunoreactive cells were lost in double-mutant mice (Figure 4F, H), concurring with previous findings outlining Arx as an alpha-cell lineage-defining factor [27,36,37]. PP-expressing cells were detected in wild type, single- and doublemutant mice although relatively rare in pancreata of $N k \times 2.2^{-/-}$and $N k \times 2.2^{-/-} A r x^{-}$newborns (Figure 4I-L).

Next, we assayed somatostatin-expressing delta-cells. Wild type delta-cells classically do not express $N k x 2.2$. Accordingly, they appeared in normal numbers in $N k x 2$.2-deficient mice (Figure 4O, [22,23]). As previously reported, the delta-cell population was found significantly increased in Arx-mutants as compared to agematched controls (2.4-fold) (Figure 4N, [27]). Hence, we expected an unopposed delta-cell differentiation in the absence of both factors. Importantly, we noticed a dramatic increase in the number of somatostatin-producing cells at all stages tested (E14.5, E18.5 and P0) as compared to wild type, Arx- or Nkx2.2-deficent pancreata (Figure 4M-P, data not shown). 

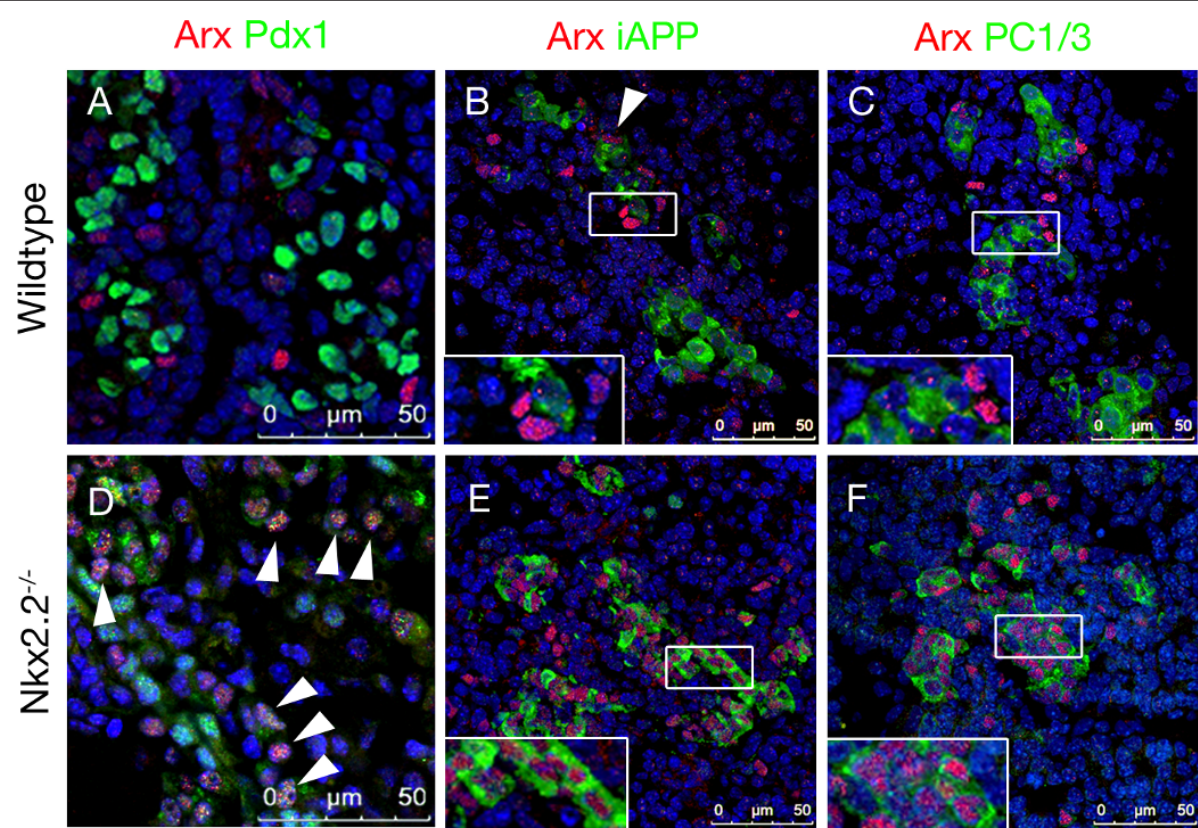

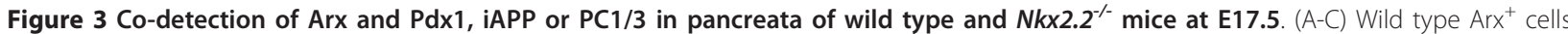
do not express Pdx1 (A) or PC1/3 (C, inset). Most Arx cells do not express iAPP (B), except in rare instances (Arrowhead). (D-F) The majority of

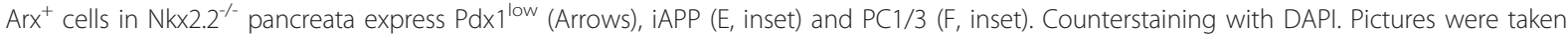
using confocal microscopy (Insets magnification: $4 \times$ ).

In P0 wild type pancreata, a small population of single-hormone ghrelin ${ }^{+}$epsilon-cells is detectable beside glucagon ${ }^{+} /$ghrelin $^{+}$alpha-cells [2]. The loss of functional Arx specifically depletes the population of glucagon ${ }^{+} /$ghrelin $^{+}$alpha-cells but does not significantly impact on the numbers of single-hormone ghrelin ${ }^{+}$epsilon-cells $[2,27]$. Similarly, glucagon ${ }^{+} /$ghrelin $^{+}$alpha-cells were found lacking in pancreata of Nkx2.2 $2^{-/-}$animals [13]. However, in the absence of both $N k \times 2.2$ and Arx, a drastic augmentation in ghrelin ${ }^{+}$cells was observed, such increase being similar to that of $N k \times 2.2^{-1-}$ pancreata (Figure 4S, T). Surprisingly, somatostatin and ghrelin co-detection revealed a great number of cells coexpressing both hormones (Figure 4X, Y). This later result was confirmed using two different sets of antighrelin and anti-somatostatin antibodies (Figure 4 and data not shown). Notably, such bi-hormonal cells were not detectable in P0 wild type, Nkx2.2- or Arx single mutant mice (Figure $4 \mathrm{U}-\mathrm{WW}$ ). Moreover, pancreata of double heterozygous mice as well as of $N k x 2.2^{-/-} A r x^{+/-}$ or $N k x 2.2^{+-}$Arx mice did not display such bi-hormonal cells (data not shown).

We further quantified the different endocrine cell subtypes present at P0 (Figure $4 \mathrm{Y}$ ). In $N k \times 2.2^{-/-}$pancreata, the numbers of ghrelin ${ }^{+}$cells was found approximately 12 times increased compared to ghrelin ${ }^{+}$cells in wild type pancreata. Interestingly, a similar augmentation in the total amount of ghrelin ${ }^{+}$cells was noted comparing pancreata of $N k x 2.2$ single and $N k x 2.2 / A r x$ double mutants; however, approximately $80 \%$ of such ghrelin ${ }^{+}$ cells also expressed the somatostatin hormone in the latter genotype. This suggests that Arx suppresses somatostatin expression in Nkx2.2 $2^{-/-}$ghrelin $^{+}$cells. It should be noted that the numbers of single-hormone positive somatostatin-producing cells observed in $N k x 2.2^{-1-} \mathrm{Arx}$ were comparable to those of $N k \times 2.2^{-/-}$single knockout and wild type pancreata. Equally important is the observation that the content of ghrelin ${ }^{+}$somatostatin $^{+}$cells found in $N k x 2.2^{-/} A r x^{-}$or of ghrelin ${ }^{+}$noted in $N k x 2.2^{-/-}$ were similar to the beta-cell numbers found in their wild type counterparts. This finding further supports the notion that beta-cells are correctly specified but fail to properly differentiate in these genotypes. Altogether, our findings demonstrate that the combined loss of $N k x 2.2$ and Arx prevents the formation of both insulin- and glucagon-expressing endocrine cells, but has no effect on the number of single-hormone positive somatostatinproducing cells. However, an alternative cell subtype develops, such cells expressing both ghrelin and somatostatin hormones.

\section{$N k x 2.2 / A r x$-deficient endocrine cells express $i A P P$ as well} as low levels of $P d x 1$ and Pax6

$P d x 1$ expression persists in developing and mature wild type beta-cells and can be found in scattered delta-cells, these two endocrine cell subtypes also expressing islet 


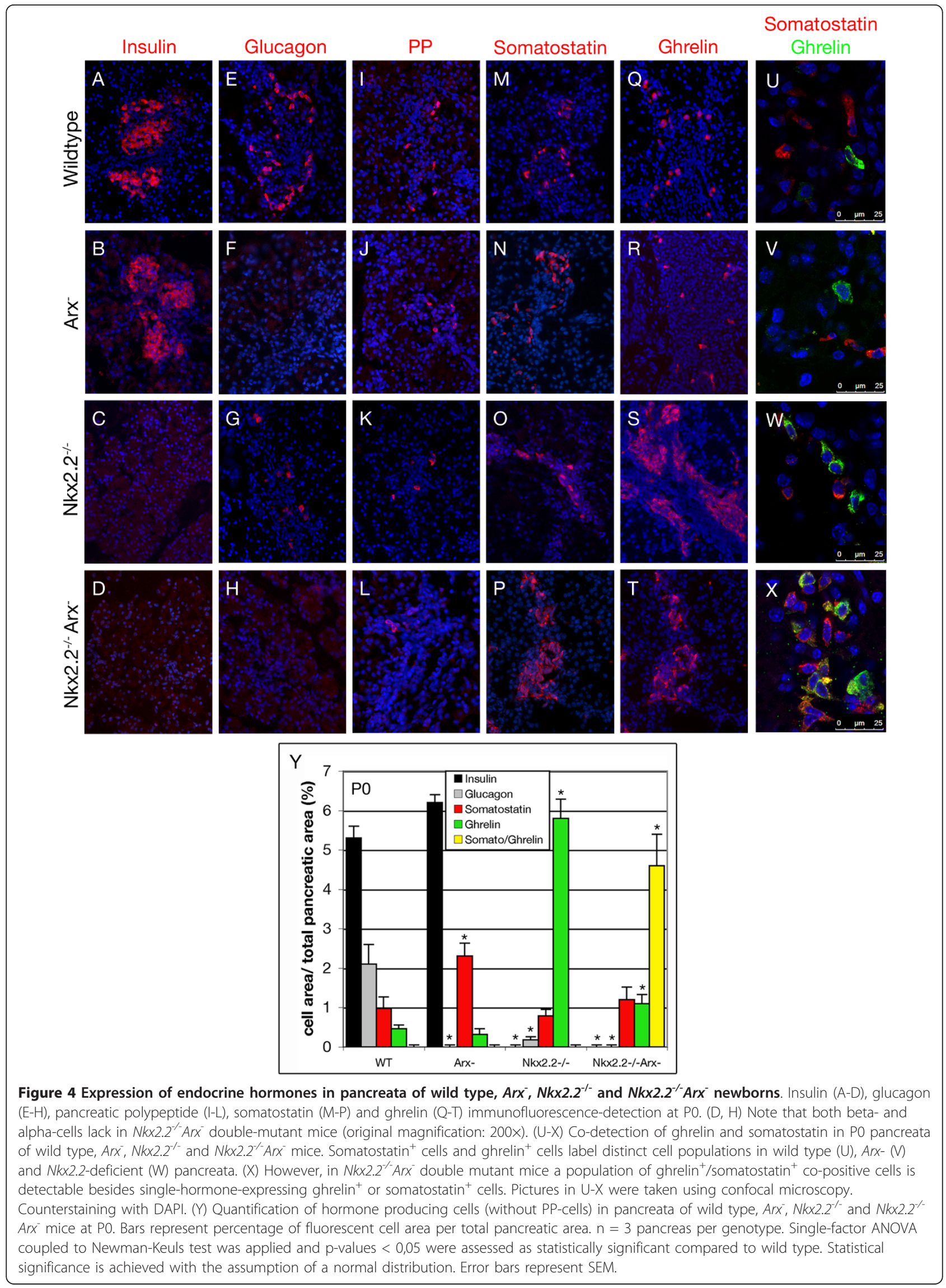


amyloid polypeptide (IAPP) ([17,43-45] and Figure 5C). Our observations prompted us to further characterize the identity of the endocrine cells present in the pancreata of $N k \times 2.2^{-/-} \mathrm{Arx}^{-}$mice by investigating the expression of Pdx1 and iAPP in association with somatostatin or ghrelin. Moreover, we also assessed the expression of the endocrine marker Pax6 that had been suggested to be Nkx2.2-dependent [13].

In contrast to the scattered expression of $\mathrm{Pdx} 1$ classically observed in delta-cells of wild type, $N k \times 2.2^{-/-}$or $A r x^{-}$embryos, Pdx1 could be detected in almost all somatostatin $^{+}$cells present in $N k \times 2.2^{-/-} A r x^{-}$double mutant pancreata. Notably, Pdx1 expression levels were markedly lower as compared to wild type pancreata but comparable to the low Pdx1 levels found in $N k \times 2.2^{-1-}$ pancreata (Figure 5D, [39]). Furthermore, all somatostatin $^{+}$cells were found to express iAPP (Figure 5F) and low levels of Pax6 (Figure 5E). Subsequent analyses of ghrelin-secreting cells in double mutant pancreata expectedly revealed that a vast majority likewise expressed these factors (Figure 5J-L). The expression of these beta-cell associated genes can also be observed in double-mutant pancreata at embryonic day 17 (Figure $5 \mathrm{O}, \mathrm{P})$. Hence, the alterations of Pdx1, iAPP and Pax6 expression appear similar in mice lacking $N k x 2.2$ and animals deficient for both $N k x 2.2$ and $A r x$, outlining the importance of Nkx2.2 in sustaining normal expression levels of these genes. Consequently, the main endocrine cell type found in pancreata of double mutant mice is characterized by the expression of ghrelin, somatostatin, Pdx $1^{\text {low }}, \mathrm{Pax}^{\text {low }}$ and iAPP. Therefore, such cells display the same beta-cell-like features as the ghrelin ${ }^{+}$cells found in $N k \times 2.2$ single mutants and differ only in somatostatin expression. Taken into account that, in $N k x 2.2$ single mutants, the population of ghrelin ${ }^{+} / \mathrm{Pdx} 1^{\text {low }} / \mathrm{iAPP}$ ${ }^{+}$cells is also expressing high levels of Arx, it is conceivable that the loss of Arx promotes ectopic somatostatin expression in such cells.

\section{Expression of Pax4 and Nkx6.1 in pancreata of normal, single- and double-mutant animals}

To further determine the developmental stage at which beta-cell differentiation is impaired in our mutant animals, we subsequently assayed the expression of the endocrine precursor marker Pax4 (Figure 6, [26,34]). Broadly expressed in the embryonic pancreas around E16.5, its expression successively declines and is rarely detectable in newborns [39]. However, low expression levels have been noted in adult beta-cells [35]. Moreover, Pax4 has been shown to be essential for the formation of beta- and delta-cells, and for the expression of a normal set of genes associated with beta-cell characteristics. In accordance with previous studies detecting Pax4 transcripts in $A r x$ - or Nkx2.2-deficient mice, we observed numerous Pax $4^{+}$cells at embryonic day 16.5 in the pancreatic epithelium of such animals using immunohistochemical detection (Figure 6B, C). We have previously reported that the Arx factor binds the Pax4 promoter and negatively regulates Pax 4 expression, thereby specifying alpha vs. beta-cell fates [36,37]. However, despite markedly elevated $\operatorname{Arx}$ transcript levels upon the loss of functional $N k x 2.2$, we did detect normal Pax $4^{+}$cell numbers in pancreata of E16.5 Nkx2.2.mice, suggesting that, in this genotype and at this age, Pax4 is not downregulated by Arx. Interestingly, the combined loss of $N k \times 2.2$ and Arx did not impact in the number of Pax $4^{+}$cells as compared to $N k \times 2.2$ mutant pancreata, thus indicating that their formation does not depend on either factor (Figure 6D, E). Notably, and in agreement with previous findings, Pax4 expression was not detectable in ghrelin ${ }^{+}$cells of wild type or mutant pancreata.

Next, we analysed the temporal expression of Nkx6.1 in pancreata of all four genotypes (Figure 7). Importantly, previous studies had shown that both Pax4 and $\mathrm{Nkx} 2.2$ are essential to maintain the expression of Nkx6.1 in developing beta-cells $[23,39]$; in the absence of either factor, a decrease in Nkx6.1 $1^{+}$cell numbers was seen from E16.5 on, progressing to a complete loss of Nkx6.1 $1^{+}$cells in newborns. The loss of Arx had no impact on Nkx6.1 expression as it was found maintained and properly located in emerging beta-cells (Figure 7F, [27]). In $N k \times 2.2^{-/-} A r x^{-}$compound mutant mice, we observed a temporal expression pattern of Nkx6.1 comparable to that of $N k x 2.2$-deficient pancreata; broadly expressed in the undifferentiated pancreatic epithelium at E15.5, the number of Nkx6.1 $1^{+}$cells was found drastically reduced at E18.5, while no Nkx6.1 $1^{+}$cells could be detected at P0 (Figure 7C, D, G, H and data not shown).

Recent studies have demonstrated that Nkx6.1 $1^{+}$cells arising during embryonic pancreatogenesis can be subdivided into Sox9 $9^{+}$and Sox9 $9^{-}$cells, representing ductal/ endocrine progenitors and committed beta-cells, respectively $[31,46,47]$. In order to characterize the Nkx6.1 ${ }^{+}$ population within the different genotypes, we codetected Nkx6.1 and Sox9 using immunofluorescence. In E15.5 wild type and $A r x$-mutant pancreata, numerous Nkx6.1 ${ }^{+}$Sox9 $9^{-}$beta-cells are detectable besides Nkx6.1 ${ }^{+}$Sox $9^{+}$progenitor cells (Figure 7I, J, M). Interestingly, in Nkx2.2-deficient genotypes, Nkx6.1 $1^{+}$cells were found associated to the uncommitted progenitor population (Figure $7 \mathrm{~K}, \mathrm{~L}, \mathrm{M}$ ). These data clearly demonstrate that the expression of $N k x 6.1$ is not dependent on Nkx2.2 activities within Sox $9^{+}$progenitor cells. However, as soon as a cell enters the endocrine lineage, $N k \times 6.1$ expression is found highly dependent on Nkx2.2. These results also imply that the steady decline in $\mathrm{Nkx}^{-1} 1^{+}$cell numbers observed in $\mathrm{Nkx} 2.2^{-/-}$pancreata, most likely 


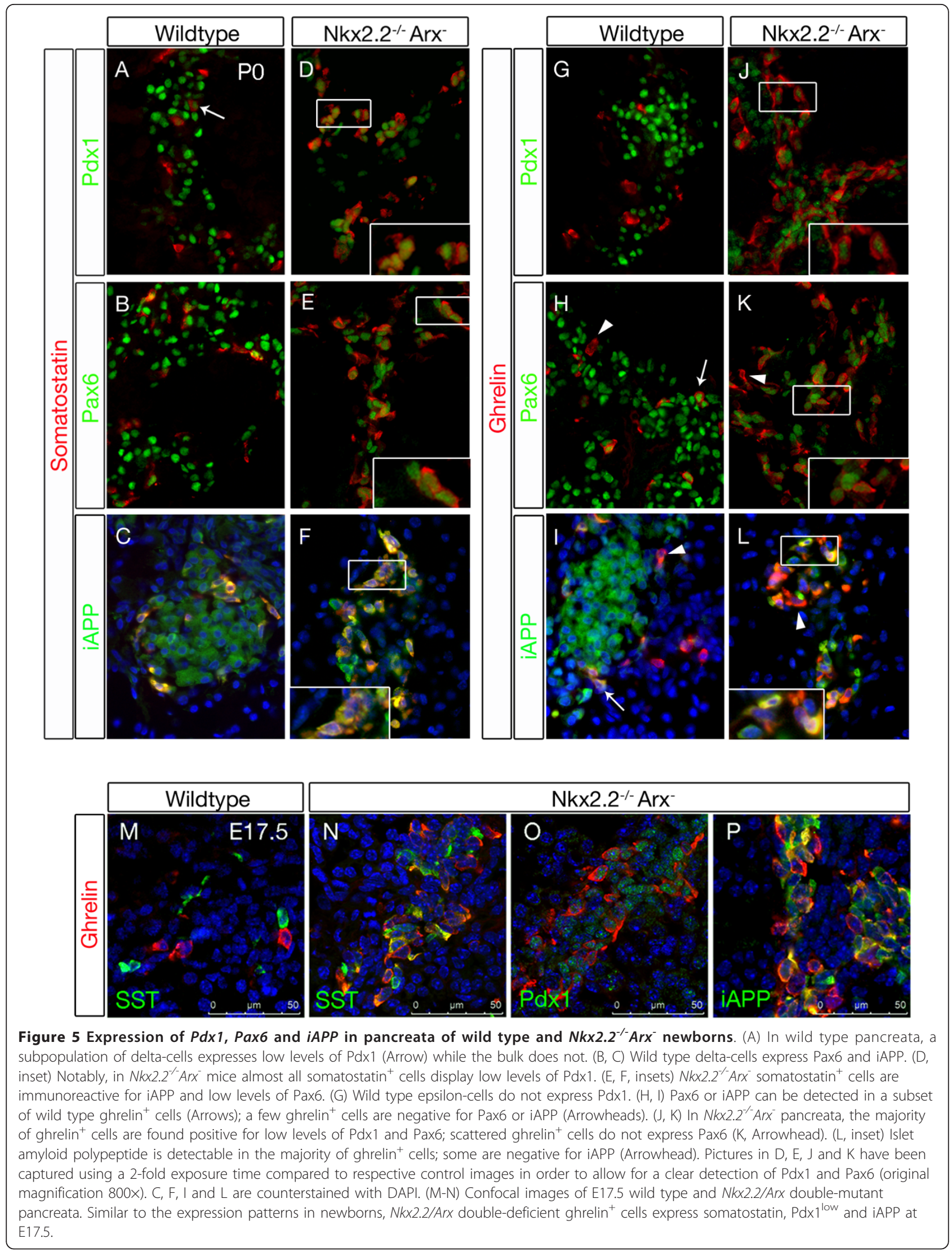




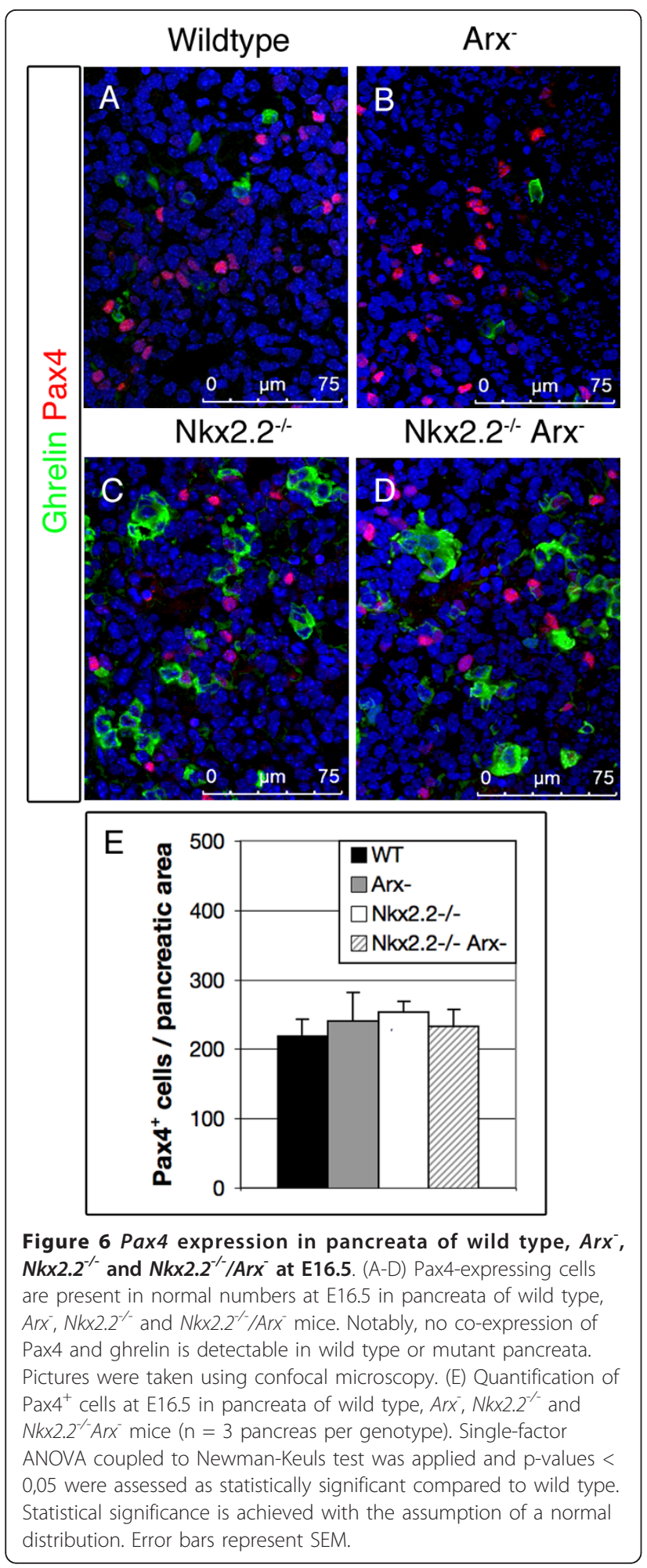

reflects the normal decrease of progenitor cells classically noted in the last days of embryonic pancreas development [47].

Taken together, our results demonstrate that Nkx2.2 and Arx are dispensable for the generation of Pax $4^{+}$ cells. Moreover, the alterations in the expression of Pdx1, Nkx6.1 and Pax6, appear similar when comparing pancreata of $N k \times 2.2$-single and $N k \times 2.2 /$ Arx compoundmutants, suggesting that the failure of beta-cell differentiation and the associated ghrelin misexpression are solely caused by the loss of $N k x 2.2$. Similarly, the dramatic alterations in alpha-cell development in $N k \times 2.2^{-/-}$ pancreata, where Arx expression is even more pronounced, sustain the notion that $N k x 2.2$ is also necessary for the acquisition of mature alpha-cell fate.

\section{Discussion}

In this study we have (re-) examined the consequences of the loss-of-function of Pax6, Arx or Nkx2.2, as well as of the combined loss of $N k x 2.2$ and $A r x$, on the development of pancreatic endocrine hormone-producing cells. Previous studies had shown that the loss of Nkx2.2 or Pax6 results in the formation of numerous ghrelin-expressing cells at the expense of the beta- and alpha-cell populations $[2,13]$. Herein, we demonstrate that the majority of such ghrelin ${ }^{+}$cells express the alpha-cell specifier Arx. However, further expression analyses focusing on ghrelin and alpha- or beta-cellrelated genes suggest a partial association of the mutant ghrelin $^{+} / \mathrm{Arx}^{+}$population to the beta-cell lineage. The combined loss of $N k x 2.2-$ and Arx likewise results in the formation of numerous ghrelin ${ }^{+}$cells at the expense of alpha- and beta- cells, whereas delta-cell formation appears unaffected. Notably, the majority of the ghrelin ${ }^{+}$ cells were, yet again, found to display some of the features classically associated to beta-cells, but also to ectopically express somatostatin, suggesting that the additional loss of Arx promotes the ectopic expression of somatostatin.

Ghrelin $^{+}$cells arising in Nkx2.2-deficient pancreata display different characteristics as compared to ghrelin ${ }^{+}$cells arising in wild type or Pax6-deficient mice

Previous reports have revealed that the loss of Pax4, $N k x 2.2$ or Pax6 is accompanied by the emergence of numerous ghrelin ${ }^{+}$cells at the expense of the beta-cell population $[2,13,33]$. Notably, in either mutant pancreas, the expression of the two other genes is detectable, rendering it difficult to attribute putative ghrelin-suppressing activities to one of the three candidates. At least for Pax4, such ghrelin-suppressing function has been demonstrated in vitro, whereas Nkx2.2 has been shown to exhibit ghrelin-activating functions in cell culture experiments [33,48]. However, Pax4 expression remains detectable in Nkx2.2- or Pax6-mutant pancreata, suggesting that ghrelin-silencing requires multiple factors. Interestingly, in all three mutants, Arx transcripts levels are found increased and Arx is often associated with ghrelin-expressing cell populations $([33,38]$, this study). 


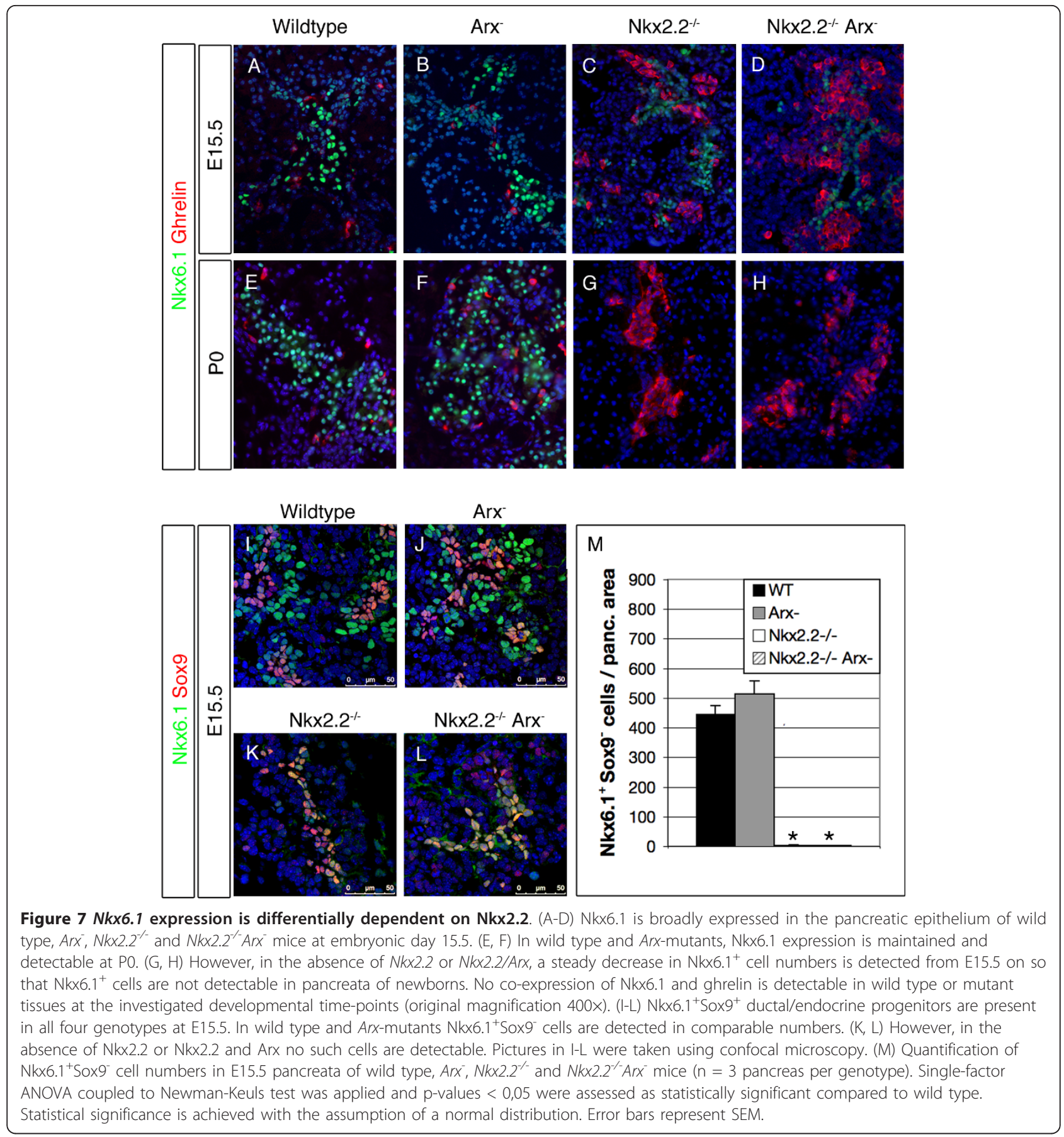

The possibility that Arx acts as a putative ghrelin-activator, however, appears unlikely as ghrelin-expression is also broadly maintained in cells arising in $N k x 2.2 / A r x$ compound mutants.

In an effort to better characterize such mutant ghrelin-expressing cells, we analysed co-expression of ghrelin and alpha-or beta-cell related markers in pancreata of wild type, $\operatorname{Pax}^{-/-}$and $N k \times 2.2^{-/-}$mice. The bulk of the $N k x 2.2$-deficient ghrelin ${ }^{+}$cells expresses Arx, iAPP,
PC1/3 and Pdx 1 and thus strongly differs from wild type epsilon-cells, excluding a specific augmentation of epsilon-cell numbers upon $N k x 2.2$ depletion. As previously suggested, our data strengthens the notion, that the majority of ghrelin ${ }^{+}$cells arising in $N k x 2.2$-deficient mice represent committed beta-cells that fail to properly differentiate [22,23].

Wang et al. suggested that Nkx2.2 acts in synergy with Pax4 during the early steps of beta-cell differentiation 
[39]. Interestingly, the population of ghrelin ${ }^{+} /$glucagon $^{+}$ cells emerging in pancreata of Pax4-deficient mice share many characteristics with the one observed in Nkx2.2deficient mice, including the expression of Arx, iAPP, $\mathrm{Pdx} 1^{\text {low }}$ and PC1/3 ([33], data not shown). It is therefore conceivable, that such cells likewise represent committed beta-cell precursors and that the presence of Nkx2.2 and Arx allows their maturation towards a glucagon-expressing state. Wang et al. also outlined that synergistic activities of Nkx2.2 and Pax4 are essential in the early steps of beta-cell differentiation in order to activate crucial factors, such as Hb9, Nkx6.1 and $\operatorname{Pdx} 1^{\text {high }}$ [39]. Furthermore, we previously demonstrated that Pax4 strongly suppresses Arx expression in early beta-cells $[27,36]$. Together with these findings, our current data provides strong evidence for the essential synergistic activity of Nkx2.2 and Pax4 to suppress Arx expression in early committed beta-cells. A strict control of Arx production appears essential as Arx is sufficient to convert mature beta-cells into PP-like or alpha-like cells [37]. The facts that Nkx2.2 is also expressed in alpha-cells and that alpha-cell development is impaired upon $N k \times 2.2$ deficiency, lead to the assumption that the lineage determining activities of both Arx and Pax4 require Nkx2.2 activity.

We also demonstrate that the lack of functional Pax6 results in the formation of ghrelin ${ }^{+} / \mathrm{Arx}^{+}$cells. Pax6 was thought to exert a more general role in the maintenance of the beta-cell identity. The presence of a few but apparently normal beta-cells in pancreata of Pax6-deficient mice even led to the suggestion of an alternate Pax6-independent pathway leading to mature beta-cells [42]. Interestingly, we frequently detected scattered insu$\operatorname{lin}^{+} /$ghrelin $^{+}$cells in such mutant pancreata. Such cells might represent a transitional state of beta-cells converting into ghrelin ${ }^{+}$cells. Tracing the lineage of insulinexpressing cells in the Pax6-deficient background would doubtless shed more light on this interesting issue. However, Pax6-deficient ghrelin ${ }^{+}$cells express neither iAPP nor Pdx1, thus differing from the ghrelin ${ }^{+}$populations arising in $N k \times 2.2$ - or Pax4-deficient pancreata. The presence of iAPP and Pdx1 in the remaining Pax6deficient beta-cells indicates that Pax6 is not necessary for the activation of these genes. However, it is conceivable that Pax6 function is essential for maintaining their expression as soon as a beta-cell reaches a certain stage of differentiation.

The almost complete loss of glucagon ${ }^{+}$cells in Pax6deficient mice indicates a more essential role of Pax6 in alpha-cells. In this context, it has been demonstrated that Pax6 binds and activates the glucagon gene $[32,40,41,49]$, however it remains unknown whether Pax6 is also involved in the determination of the alphacell lineage. The continued expression of three alpha- cell related genes (Nkx2.2, Arx, Brn4) in Pax6-deficient pancreata might be an indication for a predominant involvement of Pax6 in later stages of alpha-cell differentiation.

\section{Ghrelin $^{+} /$somatostatin $^{+}$cells arising in Nkx2.2/Arx compound mutants represent a non-delta-cell type}

Our analysis shows that the combined loss of $N k \times 2.2$ and $A r x$ prevents the formation of mature alpha- and betacells, thus confirming the requirement of Arx and Nkx2.2 activities for the formation of these cell types. However, the presence of $\mathrm{Pax} 4^{+}$cells indicates that an endocrine precursor state is attained without $N k x 2.2$ and/or $A r x$. This, and previous studies, suggest that $N k x 2.2$ is essential for the maintenance of high levels of Pdx1 and Pax6 as well as the activation of $N k x 6.1$ in developing beta-cells $[13,22,39]$. Consistent with these assumptions, the alterations found in the expression of Pdx1, Pax6 and Nkx6.1 appear similar, comparing pancreata of $N k x 2.2$ single- and $N k x 2.2 / A r x$ compound-mutant mice. These data once more imply that $A r x$ is dispensable for the beta-cell fate and that the proper expression of these genes can be attributed to $N k x 2.2$ alone.

However, the additional loss of Arx results in the formation of numerous ghrelin ${ }^{+} /$somatostatin $^{+}$cells beside populations of single-hormone positive somatostatin ${ }^{+}$or ghrelin $^{+}$cells. We did not detect ghrelin expression in delta-cells arising in wild type or either single-knockout pancreata. Together with the observation that neither Nkx2.2 nor Arx is expressed in wild type delta-cells, we conclude that such double positive cells do not represent delta-cells ectopically expressing ghrelin but rather a population comparable to the ghrelin ${ }^{+}$cells arising in $N k x 2.2$-deficient mice. This is further supported by the fact that ghrelin ${ }^{+} /$somatostatin $^{+}$cells display the same broad expression of Pdx1 ${ }^{\text {low }}$ as observed in Nkx2.2-deficient ghrelin ${ }^{+}$cells. Hence, we conclude that $80 \%$ of the ghrelin $^{+}$cells initiate somatostatin expression upon the additional loss of Arx. Not all ghrelin-labelled cells coexpress somatostatin in double-mutant pancreata. This might be attributed to their distinct predeterminations and partially reflect the presence of normal epsilon-cells. Nevertheless, our data also imply that Arx or a not yet identified downstream mediator exerts a suppressive effect on somatostatin expression. In this context, previous studies demonstrated that Arx activities strongly antagonize delta-cell formation [27,36,37]. However, whether Arx directly antagonizes somatostatin expression would require further investigations.

\section{Conclusions}

Our data indicate that although proper endocrine differentiation/hormone expression is impaired in Pax6- or Nkx2.2-deficient pancreata, committed cells retain some 
of the characteristics normally associated with mature beta-cells (Figure 8). Our analysis of $N k \times 2.2 / A r x$ singleand double-mutant pancreata allow us, together with the data from others, to conclude that both Pax4 and Arx require the activity of $N k x 2.2$ in order to maintain the transcriptional cascades initiated in early committed beta- and alpha-cell precursors, respectively. Our findings also suggest that one of the coupled functions of Nkx2.2 and Pax4 is the control of Arx gene activity in committed beta-cell precursors.

\section{Methods}

\section{Animals}

Mice heterozygous for both $N k x 2.2$ and Arx were generated by crossing $N k x 2.2^{+/-}$males [22] with $A r x^{+/-}$ females [27] and maintained in an NMRI background. Double heterozygous females were further bred with Nkx2.2 $2^{+/-}$males. Moreover, we utilized tissue from Pax6-nullizygous mice previously described by [24]. Genotyping was performed as described in [22,24,27]. Animal care and experimental use were approved by the Ordnungsamt der Stadt Göttingen, Germany.

\section{Immunohistochemistry}

Pancreata were fixed 30 minutes in $4 \%$ paraformaldehyde at $4^{\circ} \mathrm{C}$, dehydrated through graded alcohols and embedded in paraffin. $8 \mu \mathrm{m}$ (P0) or 5 um-sections (E15.5-E17.5) were rehydrated and blocked in PBS containing $10 \%$ inactivated fetal calf serum for $60 \mathrm{~min}$. Primary antibodies were diluted in the same medium, applied onto sections, and incubated overnight at $4{ }^{\circ} \mathrm{C}$. Slides were washed in PBS and incubated for $45 \mathrm{~min}$ with the appropriate secondary antibody diluted in PBS containing $10 \%$ inactivated fetal calf serum. Slides were washed in PBS, mounted with DAPI, and viewed by fluorescent or confocal microscopy.

The primary antibodies used were as follows: rabbit anti-Brn4 1/200 [kindly provided by A. Ryan (McGill University, Montreal, QC)]; guinea-pig anti-insulin 1/ 1000 (Dako); guinea-pig anti-insulin 1/1000 (Linco), guinea-pig anti-glucagon 1/1000 (Linco); rabbit anti-somatostatin 1/600 (Dako); rat anti-somatostatin 1/200 (Millipore); rabbit anti-PP diluted 1/200 (Linco); mouse anti-ghrelin $1 / 1500$ [kindly provided by C. Tomasetto (Université Louis Pasteur, Strasbourg, France)]; goat anti-ghrelin 1/50 (Santa Cruz), rabbit anti-ghrelin 1/ 1000 (Millipore), rabbit anti-Amylin 1/300 (Phoenix Pharmaceuticals); rabbit anti-Nkx6.1 diluted 1/3000; rabbit anti-Pdx1 diluted $1 / 1000$ [kindly provided by $\mathrm{C}$. Wright (Vanderbilt University, Nashville, TN)]; rabbit anti-Pax6 1/1000 (Covance); rabbit anti-Pax4 1/1000 [kindly provided by B. Sosa-Pineda (St. Jude Children's

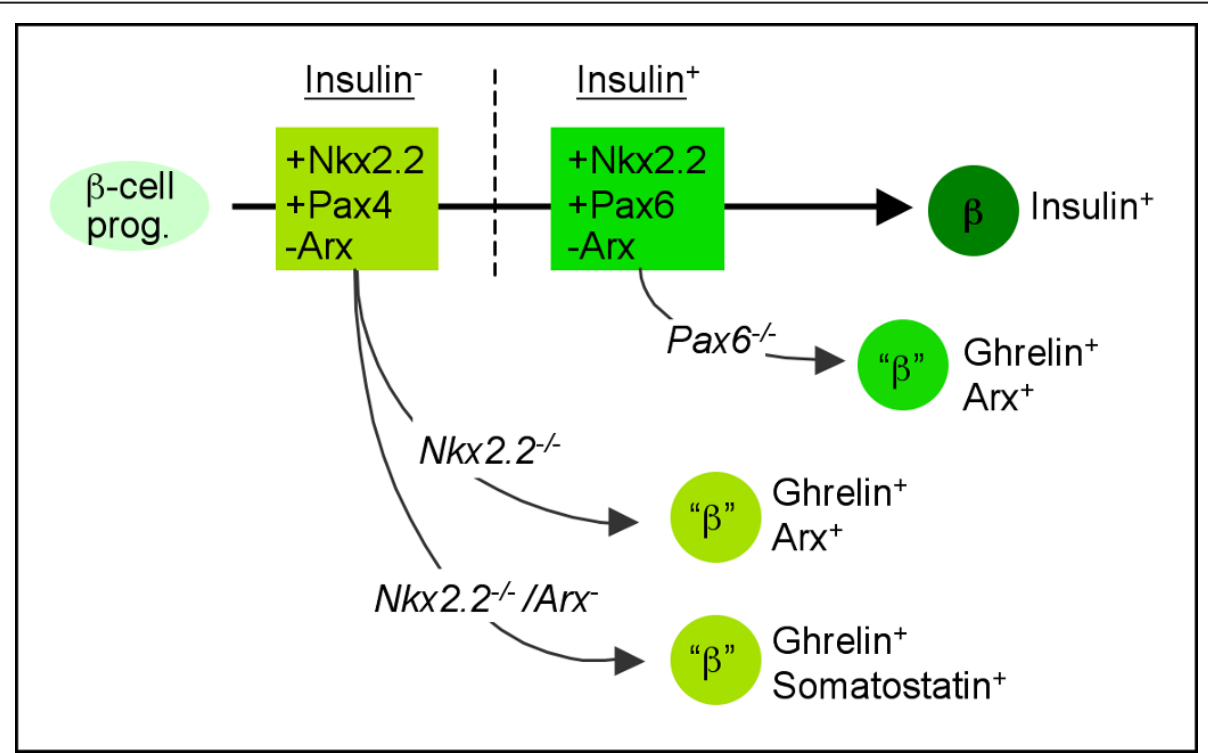

Figure 8 Schematic representation of transcription factor combinations guiding beta-cell differentiation. Following the loss of $N k \times 2.2$ or $P a \times 6$, endocrine cells retain some beta-cell characteristics, such as the expression of $i A P P, P d \times 1$ and/or $P C 1 / 3$ (indicated as " $\beta$ "). Rectangles describe transcription factor combinations required to maintain the embryonic beta-cell differentiation program pre- and post-insulin expression (light and dark green, respectively). Shortly after the activation of Ngn3, both Nkx2.2 and Pax4 are necessary for the expression of additional beta-cell specific TF's such as Nkx6.1 (not depicted). Concomitantly, this combination of TF's prevents the misexpression of Arx and ghrelin in committed beta-cells. In the absence of both Nkx2.2 and Arx, endocrine cells retain the same beta-cell features as noted in the absence of Nkx2.2 only, but then express ghrelin and somatostatin. Pax6 appears necessary for maintaining normal beta-cell identity at later stages of differentiation, probably shortly after insulin activation. At that stage Pax6 presumably takes over some of the functions previously exerted by Pax4, whose expression decreases. 
Research Hospital, Memphis, TN)], rabbit anti-PC1/3 diluted 1/500 (Millipore), rabbit anti-Arx diluted 1/250, guinea-pig anti-Arx diluted $1 / 500$ and rabbit anti-Sox 9 1/200 (Millipore).

The secondary antibodies (invitrogen, dilution 1/1000) used for immunofluorescence were as follows: 594-alexa anti-mouse; 488-alexa anti-mouse, 594-alexa anti-rabbit; 488-alexa anti-rabbit; 594-alexa anti-guinea pig; 488alexa anti-guinea pig; 594-alexa anti-goat and 488-alexa anti-goat. Images were taken using either a Leica TCS confocal-laser scanning microscope or an Olympus BX60 fluorescent microscope.

\section{Morphometric Analyses}

P0 pancreata from wild type, $A r x^{-}, N k x 2.2^{-/-}$and $N k \times 2.2^{--} A r x^{-}$mice were serially sectioned and every twelfth section (10 sections per pancreas) was stained for insulin, glucagon and ghrelin or somatostatin and ghrelin. Non-overlapping pictures were taken from every section using $10 \times$ magnification and same exposure times. Total pancreatic area and fluorescent cell area were determined using the histogram- and colour range functions in Adobe Photoshop. Results are displayed as fluorescent cell area per total pancreatic area. In order to assess the numbers of $\mathrm{Arx}^{+}, \mathrm{Pax}^{+}$(at E16.5) or Nkx6.1 $1^{+}$Sox9 $9^{-}$cells (at E15.5) pancreata were sectioned (5 um) and every eighth section (6 sections per pancreas) was stained with the respective antibodies. The numbers of $\mathrm{Arx}^{+}, \mathrm{Pax}^{+}$or $\mathrm{Nkx} 6.1^{+} \mathrm{Sox}^{-}$cells were counted by microscopy and subsequently standardized to the pancreatic area.

For both morphometric analysis a single-factor ANOVA coupled to Newman-Keuls test was applied and $\mathrm{p}$-values $<0,05$ were assessed as statistically significant compared to wild type ( $\mathrm{n}=3$ pancreata for each genotype). Statistical significance is achieved with the assumption of a normal distribution. In order to determine the percentages of copositive cells $\left(\mathrm{Arx}^{+} /\right.$glucagon ${ }^{+}, \mathrm{Brn}^{+} /$ghrelin $^{+}, \mathrm{Arx}^{+} /$ghrelin $^{+}$, insulin $^{+} /$ghrelin $^{+}, \mathrm{Pdx} 1$ ${ }^{+} /$ghrelin $^{+}, \mathrm{iAPP}^{+} /$ghrelin $^{+}$and $\mathrm{PC} 1 / 3^{+} /$ghrelin $^{+}$), 10 microscopy fields (per pancreas) of representative areas were counted. Error bars represent SEM.

\section{mRNA Quantification}

Total RNA was isolated with the RNeasy Plus Mini Kit (Qiagen) using whole pancreata at E16.5 ( $\mathrm{n}=3$ per genotype). 5 ug total RNA of each pancreas was subjected to cDNA synthesis with the SuperScript II Reverse Transcriptase Kit (invitrogen) following the manufacturer's instructions. The amount of Arx (QT00162904), Pax6 (QT01052786) and Nkx2.2 (QT00495502) transcripts was assessed relative to Gusb (QT00176715) using the QuantiTect SYBR Green PCR Kit from
Qiagen. Quantitative PCR's were processed using the eppendorf Mastercycler realplex system.

\section{Glucose levels}

Glucose levels were determined with the One Touch Glucose monitoring kit (Johnson \& Johnson) using $15 \mathrm{ul}$ of peripheral blood.

\section{Acknowledgements and Fundings}

We are most grateful to A. Ryan, C. Tomasetto, C. Wright and B. Sosa-Pineda for providing antibodies. The authors are supported by the Max-Planck Society, the Dr. H. Storz and Alte Leipziger foundation, the Juvenile Diabetes Research Foundation, the European Research Council, the INSERM AVENIR program, the INSERM, the Fondation pour la Recherche Médicale, the Agence Nationale de la Recherche, the Schlumberger Foundation, the Bundesministerium für Bildung und Forschung (BMBF: 01 KU0906), Club Isatis, Mr. and Mrs. Olivier Dorato, and the NIH Beta Cell Biology Consortium (DK 072495). We thank L. Sussel for Nkx2.2 mice.

\section{Author details}

${ }^{1}$ Department of Molecular Cell Biology, Max-Planck Institute for Biophysical Chemistry, Am Fassberg, D-37077 Göttingen, Germany. ${ }^{2}$ Diabetes Genetics team, Inserm U636, FR-06108 Nice, France. ${ }^{3}$ Université de Nice SophiaAntipolis, FR-06108 Nice, France. ${ }^{4}$ Department of Clinical Neurophysiology, University of Göttingen, Robert-Koch Strasse 40, D-37075 Göttingen, Germany. ${ }^{5}$ Department of Developmental Biology, Hagedorn Research Institute, Niels Steensensvej 6, DK-2820 Gentofte, Denmark.

\section{Authors' contributions}

SK designed the study, carried out all experiments, and wrote the manuscript. PC, AM and PS conceived the study, and participated in its design and coordination and helped to draft and write the manuscript. All authors read and approved the final manuscript.

\section{Competing interests}

The authors declare that they have no competing interests.

Received: 6 May 2011 Accepted: 31 August 2011

Published: 31 August 2011

\section{References}

1. Adrian TE, Bloom SR, Hermansen K, Iversen J: Pancreatic polypeptide, glucagon and insulin secretion from the isolated perfused canine pancreas. Diabetologia 1978, 14:413-7.

2. Heller RS, Jenny M, Collombat P, Mansouri A, Tomasetto C, Madsen OD, Mellitzer G, Gradwohl G, Serup P: Genetic determinants of pancreatic epsilon-cell development. Dev Biol 2005, 286:217-24.

3. Korbonits M, Goldstone AP, Gueorguiev M, Grossman AB: Ghrelin-a hormone with multiple functions. Front Neuroendocrinol 2004, 25:27-68.

4. Roncoroni L, Violi V, Montanari M, Muri M: Effect of somatostatin on exocrine pancreas evaluated on a total external pancreatic fistula of neoplastic origin. Am J Gastroenterol 1983, 78:425-8.

5. Wierup N, Svensson H, Mulder H, Sundler F: The ghrelin cell: a novel developmentally regulated islet cell in the human pancreas. Regul Pept 2002, 107:63-9.

6. Dezaki K, Sone H, Yada T: Ghrelin attenuates glucose-induced insulin release in an autocrine/paracrine manner in pancreatic islets. Diabetologia 2006, 49:304-305.

7. Dezaki K, Sone H, Yada T: Ghrelin is a physiological regulator of insulin release in pancreatic islets and glucose homeostasis. Pharmacology \& Therapeutics 2008, 118:239-249.

8. Herrera PL, Huarte J, Sanvito F, Meda P, Orci L, Vassalli JD: Embryogenesis of the murine endocrine pancreas; early expression of pancreatic polypeptide gene. Development 1991, 113:1257-65.

9. Offield MF, Jetton TL, Labosky PA, Ray M, Stein RW, Magnuson MA, Hogan BL, Wright CV: PDX-1 is required for pancreatic outgrowth and differentiation of the rostral duodenum. Development 1996, 122:983-95. 
10. Pictet RL, Clark WR, Williams RH, Rutter WJ: An ultrastructural analysis of the developing embryonic pancreas. Dev Biol 1972, 29:436-67.

11. Teitelman G, Guz Y, Ivkovic S, Ehrlich M: Islet injury induces neurotrophin expression in pancreatic cells and reactive gliosis of peri-islet Schwann cells. J Neurobiol 1998, 34:304-18.

12. Upchurch BH, Aponte GW, Leiter AB: Expression of peptide YY in all four islet cell types in the developing mouse pancreas suggests a common peptide YY-producing progenitor. Development 1994, 120:245-52.

13. Prado CL, Pugh-Bernard AE, Elghazi L, Sosa-Pineda B, Sussel L: Ghrelin cells replace insulin-producing beta cells in two mouse models of pancreas development. Proc Natl Acad Sci USA 2004, 101:2924-9.

14. Miller K, Kim A, Kilimnik G, Jo J, Moka U, Periwal V, Hara M: Islet formation during the neonatal development in mice. PLoS One 2009, 4:e7739.

15. Gu G, Brown JR, Melton DA: Direct lineage tracing reveals the ontogeny of pancreatic cell fates during mouse embryogenesis. Mech Dev 2003, 120:35-43

16. Jonsson J, Carlsson L, Edlund T, Edlund H: Insulin-promoter-factor 1 is required for pancreas development in mice. Nature 1994, 371:606-9.

17. Serup P, Petersen HV, Pedersen EE, Edlund H, Leonard J, Petersen JS, Larsson LI, Madsen OD: The homeodomain protein IPF-1/STF-1 is expressed in a subset of islet cells and promotes rat insulin 1 gene expression dependent on an intact E1 helix-loop-helix factor binding site. Biochem J 1995, 310(Pt 3):997-1003.

18. Apelqvist A, Li H, Sommer L, Beatus P, Anderson DJ, Honjo T, Hrabe de Angelis $\mathrm{M}$, Lendahl $\mathrm{U}$, Edlund $\mathrm{H}$ : Notch signalling controls pancreatic cell differentiation. Nature 1999, 400:877-81.

19. Gradwohl G, Dierich A, LeMeur M, Guillemot F: neurogenin3 is required for the development of the four endocrine cell lineages of the pancreas. Proc Natl Acad Sci USA 2000, 97:1607-11.

20. Gu G, Dubauskaite J, Melton DA: Direct evidence for the pancreatic lineage: NGN3+ cells are islet progenitors and are distinct from duct progenitors. Development 2002, 129:2447-57.

21. Schwitzgebel VM, Scheel DW, Conners JR, Kalamaras J, Lee JE, Anderson DJ, Sussel L, Johnson JD, German MS: Expression of neurogenin3 reveals an islet cell precursor population in the pancreas. Development 2000, 127:3533-42.

22. Sussel L, Kalamaras J, Hartigan-O'Connor DJ, Meneses JJ, Pedersen RA, Rubenstein $\mathrm{J}$, German MS: Mice lacking the homeodomain transcription factor Nkx2.2 have diabetes due to arrested differentiation of pancreatic beta cells. Development 1998, 125:2213-21.

23. Sander M, Sussel L, Conners J, Scheel D, Kalamaras J, Cruz F Dela, Schwitzgebel V, Hayes-Jordan A, German M: Homeobox gene Nkx6.1 lies downstream of Nkx2.2 in the major pathway of beta-cell formation in the pancreas. Development 2000, 127:5533-40.

24. St-Onge L, Sosa-Pineda B, Chowdhury K, Mansouri A, Gruss P: Pax6 is required for differentiation of glucagon-producing alpha-cells in mouse pancreas. Nature 1997, 387:406-9.

25. Heller RS, Stoffers DA, Liu A, Schedl A, Crenshaw EB, Madsen OD, Serup P: The role of Brn4/Pou3f4 and Pax6 in forming the pancreatic glucagon cell identity. Dev Biol 2004, 268:123-34.

26. Sosa-Pineda B, Chowdhury K, Torres M, Oliver G, Gruss P: The Pax4 gene is essential for differentiation of insulin-producing beta cells in the mammalian pancreas. Nature 1997, 386:399-402.

27. Collombat P, Mansouri A, Hecksher-Sorensen J, Serup P, Krull J, Gradwohl G, Gruss P: Opposing actions of Arx and Pax4 in endocrine pancreas development. Genes Dev 2003, 17:2591-603.

28. Jorgensen MC, Ahnfelt-Ronne J, Hald J, Madsen OD, Serup P, HecksherSorensen J: An illustrated review of early pancreas development in the mouse. Endocr Rev 2007, 28:685-705.

29. Doyle MJ, Loomis ZL, Sussel L: Nkx2.2-repressor activity is sufficient to specify alpha-cells and a small number of beta-cells in the pancreatic islet. Development 2007, 134:515-23.

30. Doyle MJ, Sussel L: Nkx2.2 regulates beta-cell function in the mature islet. Diabetes 2007, 56:1999-2007.

31. Schaffer $A E$, Freude KK, Nelson SB, Sander M: Nkx6 transcription factors and Ptf1a function as antagonistic lineage determinants in multipotent pancreatic progenitors. Dev Cell 2010, 18:1022-9.

32. Sander M, Neubuser A, Kalamaras J, Ee HC, Martin GR, German MS: Genetic analysis reveals that PAX6 is required for normal transcription of pancreatic hormone genes and islet development. Genes Dev 1997, 11:1662-73.
33. Wang Q, Elghazi L, Martin S, Martins I, Srinivasan RS, Geng X, Sleeman M, Collombat P, Houghton J, Sosa-Pineda B: Ghrelin is a novel target of Pax4 in endocrine progenitors of the pancreas and duodenum. Dev Dyn 2008, 237:51-61.

34. Greenwood AL, Li S, Jones K, Melton DA: Notch signaling reveals developmental plasticity of $\operatorname{Pax} 4(+)$ pancreatic endocrine progenitors and shunts them to a duct fate. Mech Dev 2007, 124:97-107.

35. Collombat P, Xu X, Ravassard P, Sosa-Pineda B, Dussaud S, Billestrup N, Madsen OD, Serup P. Heimberg H, Mansouri A: The ectopic expression of Pax4 in the mouse pancreas converts progenitor cells into alpha and subsequently beta cells. Cell 2009, 138:449-62.

36. Collombat P, Hecksher-Sorensen J, Broccoli V, Krull J, Ponte I, Mundiger T, Smith J, Gruss P, Serup P, Mansouri A: The simultaneous loss of Arx and Pax4 genes promotes a somatostatin-producing cell fate specification at the expense of the alpha- and beta-cell lineages in the mouse endocrine pancreas. Development 2005, 132:2969-80

37. Collombat P, Hecksher-Sorensen J, Krull J, Berger J, Riedel D, Herrera PL, Serup P. Mansouri A: Embryonic endocrine pancreas and mature beta cells acquire alpha and PP cell phenotypes upon Arx misexpression. J Clin Invest 2007, 117:961-70.

38. Chao CS, Loomis ZL, Lee JE, Sussel L: Genetic identification of a novel NeuroD1 function in the early differentiation of islet alpha, PP and epsilon cells. Dev Biol 2007, 312:523-32.

39. Wang J, Elghazi L, Parker SE, Kizilocak H, Asano M, Sussel L, Sosa-Pineda B: The concerted activities of Pax4 and Nkx2.2 are essential to initiate pancreatic beta-cell differentiation. Dev Biol 2004, 266:178-89.

40. Gosmain Y, Marthinet E, Cheyssac C, Guerardel A, Mamin A, Katz LS, Bouzakri K, Philippe J: Pax6 controls the expression of critical genes involved in pancreatic \{alpha\} cell differentiation and function. $J$ Biol Chem 2010, 285:33381-93.

41. Katz LS, Gosmain Y, Marthinet E, Philippe J: Pax6 regulates the proglucagon processing enzyme PC2 and its chaperone 7B2. Mol Cell Biol 2009, 29:2322-34.

42. Nishimura W, Rowan S, Salameh T, Maas RL, Bonner-Weir S, Sell SM Sharma A: Preferential reduction of beta cells derived from Pax6-MafB pathway in MafB deficient mice. Dev Biol 2008, 314:443-56.

43. Ahlgren $\mathrm{U}$, Jonsson J, Edlund $\mathrm{H}$ : The morphogenesis of the pancreatic mesenchyme is uncoupled from that of the pancreatic epithelium in IPF1/PDX1-deficient mice. Development 1996, 122:1409-16.

44. Ohlsson $\mathrm{H}$, Karlsson $\mathrm{K}$, Edlund T: IPF1, a homeodomain-containing transactivator of the insulin gene. Embo J 1993, 12:4251-9.

45. Miller CP, McGehee RE Jr, Habener JF: IDX-1: a new homeodomain transcription factor expressed in rat pancreatic islets and duodenum that transactivates the somatostatin gene. Embo J 1994, 13:1145-56.

46. Lynn FC, Smith SB, Wilson ME, Yang KY, Nekrep N, German MS: Sox9 coordinates a transcriptional network in pancreatic progenitor cells. Proc Natl Acad Sci USA 2007, 104:10500-5.

47. Seymour PA, Freude KK, Tran MN, Mayes EE, Jensen J, Kist R, Scherer G, Sander M: SOX9 is required for maintenance of the pancreatic progenitor cell pool. Proc Natl Acad Sci USA 2007, 104:1865-70.

48. Hill JT, Chao CS, Anderson KR, Kaufman F, Johnson CW, Sussel L: Nkx2.2 activates the ghrelin promoter in pancreatic islet cells. Mol Endocrinol 2010, 24:381-90.

49. Andersen FG, Heller RS, Petersen HV, Jensen J, Madsen OD, Serup P: Pax6 and $\mathrm{Cd} \times 2 / 3$ form a functional complex on the rat glucagon gene promoter G1-element. FEBS Lett 1999, 445:306-10.

doi:10.1186/1471-213X-11-52

Cite this article as: Kordowich et al: Arx and Nkx2.2 compound deficiency redirects pancreatic alpha- and beta-cell differentiation to a somatostatin/ghrelin co-expressing cell lineage. BMC Developmental Biology 2011 11:52. 